\title{
УAK 338
}

DOI: 10.17150/2587-7445.2021.5(4).223-231

\section{О причинах устойчивого развития экономики Китая в XX-XXI вв.}

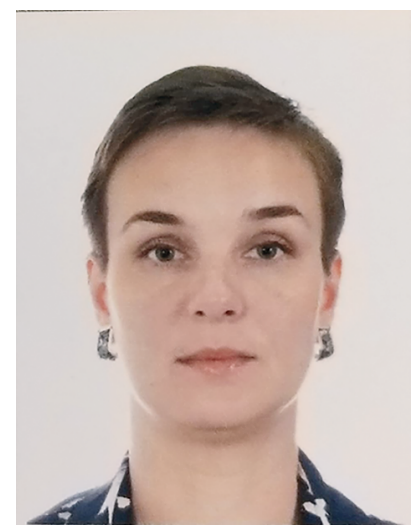

\section{М.А. Бамашова}

Байкальский государственный университет,

г. Иркутск, Российская Федерация

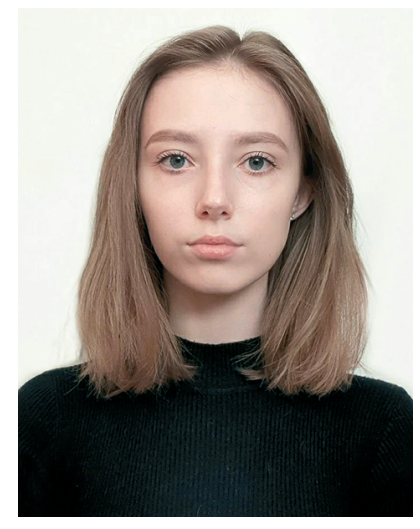

\section{А.А. Труфанова}

Байкальский государственный университет,

г. Иркутск, Российская Федерация

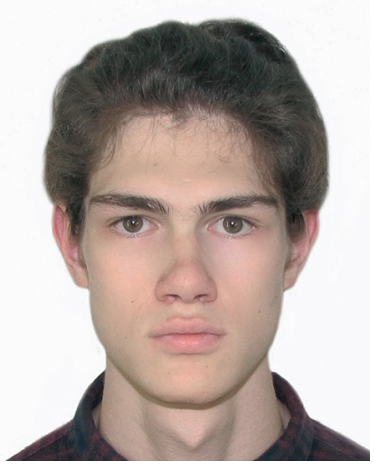

\section{М.И. Трошкин}

Байкальский государственный университет,

г. Иркутск, Российская Федерация
Аннотация. Как известно, мировая экономика представ^яет собой гибкую систему взаимоотношений ее к^ючевых субъектов, которая оказывается напрямую подверженной постоянным воздействиям как со стороны внутренних, так и внешних факторов. К числу последних, следует относить процессы глобализации, интеграции, либерализации, транснационализации и др. Они коренным образом меняют правила организации и ведения международных экономических отношений. Те страны, которые сумели вовремя оценить масштаб надвигающихся изменений и гибко среагировать на них посреАством корректировок национальной макроэкономической политики, смогли занять ведущие места в структуре современного мирового порядка. Ярким примером такого государства является Китай, который, несмотря на Аогоняющий тип развития, Аостиг по ряду показателей уровня развитых стран и стал оАним из значимых полюсов в структуре современного мирового поряака.

Проведенное авторами статьи исследование показало, что выйти на такой результат КНР уАалось благодаря грамотным реформам, начатым еще в 70-х гг. XX в. Аэн Сяопином и продолжаемым, с учетом ведущих мировых тенденций, по настоящее время. Выбор руководством страны в качестве флагмана дальнейшего поступательного развития экономики страны IT-сектора уже в настоящее время приносит Китаю значимую пользу стратегического характера.

Ключевые слова. Мировая экономика, Китай, экономические реформы, IT-сектор. 
Аата поступления:

18.10.2021

Аата принятия к печати:

14.12.2021

Аата онлайн-размещения:

30.12.2021

\section{0世纪-21世纪中国经济持续稳定发展的原因}

M.A. Balashova

贝加尔国立大学， 伊尔库茨克市，俄罗斯联

\section{A.A. Trufanova}

贝加尔国立大学， 伊尔库茨克市，俄罗斯联

\section{M.I. Troshkin}

贝加尔国立大学， 伊尔库茨克市，俄罗斯联

结稿日期：2021年10月18日 出版日期：2021年12月14日 网上出版日期：2021年12月30日
摘要 : 众所周知，世界经济是其他关键主体相互关系的灵 活系统，它长期直接受到外部和内部因素的影响。外部因素 主要指全球化、一体化、自由化、跨国化等。它们从根本上 改变着组织和开展国际经济关系的规则。那些能及时评估导 向因素规模，并通过调整本国宏观经济政策以灵活应对导向因 素的国家，可在世界秩序结构中占据主导地位。中国便是典型 的例子，即使中国是追赶型发展，但在多项指标上中国达到 了发达国家的水平，成为现代世界秩序结构中重要的一极。

本文作者研究发现，中国取得的成就得益于20世纪80年代 邓小平结合世界发展主流趋势倡导并持续至今的改革开放政 策。现如今，国家领导层选择IT行业为国家前进发展的主要 导向，也给中国带来了巨大的战略性成果。

关键词：世界经济，中国，经济改革，IT-行业。

\section{On the Reasons of China's Stable Economic Development in the XX - XXI Centuries}

\section{M.A. Balashova \\ Baikal State University, Irkutsk, Russian Federation}

\section{A.A. Trufanova}

Baikal State University, Irkutsk, Russian Federation

\section{M.I. Troshkin}

Baikal State University, Irkutsk, Russian Federation

Received: 2021 October 18 Accepted: 2021 December 14 Available online: 2021 December 30
Abstract. As is well known, the global economy is a flexible system of relationships between its key actors, and it is directly subject to the constant impact of both internal and external factors. Among the latter are the processes of globalization, integration, liberalization, transnationalization and others. They fundamentally change the rules of organization and conduct of international economic relations. Those countries that were able to duly assess the scale of imminent changes and flexibly respond to them by adjusting national macroeconomic policies were able to take leading positions in the structure of the modern world order. A striking example of such a state is China, which, despite its catching-up type of development, has reached the level of developed countries in a number of indicators and has become one of the significant poles in the structure of the modern world order.

The study conducted by the authors of the article showed that the PRC managed to achieve such a result due to the competent reforms initiated in the 1970 s by Deng Xiaoping and still ongoing taking into account best world practices.

The country's leadership's choice of the IT sector as a flagship for further progressive development of the country's economy has already brought China significant benefits of a strategic nature.

Keywords. World economy, China, economic reforms, IT-sector. 
Сложившаяся во второй половине XX в. структура мирового порядка свидетельствует об альтернативности трактовок неравномерности развития мировой экономики. Большинство специалистов весьма обоснованно утвержАают, что современный мировой порядок в чистом виАе ОАноПолярен. АбсолютнЫм лиАером являются США, остальные страны развиваются в том объеме и направлении, которые становятся Аля них Аостижимыми в результате проводимой США внутри- и внешнеэкономической политики. ПреАставительным является количество исследователей, доказывающих биполярный характер развития международных экономических отношений. Наряду с США, вторым значимым полюсом они называют КНР, которая по емкости своей экономики не уступает США, Аемонстрирует высочайшие темпы промышленного производства, проводит грамотные макроэкономические реформы, привлекающие в страну иностранные технологии, капитал, рабочую силу. Есть и третья точка зрения - трактовать современный мировой поряАок следует как многополярный. Наряду с США и KHР, показателей высокого уровня жизни, объемов и темпов производства, относительной в условиях глобализации 4.0 независимости в проведении собственной внури- и внешнеэкономической политики, успешности в отражении внешних угроз удалось Аостичь странам ЕС, в первую очереАь - ФРГ и Франции, ныне независимой от соответствующего интеграционного объединения Великобритании, в Азии - Японии и ряау Аругих государств мира.

Мы согласны с тем, что, исходя из современных тенденций развития мировой экономики, право на существование имеют все три позиции. ОАнако, основываясь на фактологическом материале, разАеляем точку зрения специалистов о биполярности структуры мирового порядка в XXI в.
Несмотря на ужесточающуюся конкурентную борьбу, как на микро, так и на макроуровнях экономического анализа, из развивающихся стран фактически только Китаю удалось совершить фантастический прорыв в экономическом, технологическом развитии, за исторически короткий срок обогнать по значению ряда макроэкономических показателей многие развитые страны мира и составить реальную конкуренцию США [1, с. 2].

Только за последнее Аесятилетие емкость его экономики, стоимостные объемы экспорта и импорта увеличились более чем в Ава раза, а объем накопленных прямых иностранных инвестиций (ПИИ) - в три раза (табл. 1).

За этот же период значительно возросли значения таких относительных показателей, характеризующих степень открытости экономики страны, как объем экспорта на душу населения, Аоля накопленных ПИИ в валовом внутреннем продукте (ВВП), объем накопленных ПИИ на Аушу населения, Аоля иммигрантов в общей численности населения (табл. 2). При этом снижение экспортной (Кэ), импортной (Ки) и внешнеторговой квот (Квнеш) КНР никак не связано со снижением внешнеторгового потенциала страны. Оно объясняется значительным темпом прироста ВВП наА соответствующими стоимостными потоками товаров, пересекающих границу страны.

Начиная с 2014 г. Китай является мировым милером по показателю ВВП по паритету покупательной способности (ППС) (табл. 3). Его значение превышает по Аанным 2019 г. соответствующий показатель в таких развитых странах как: США (21 433 млрА Аомм.), Япония (5 451 м^рА Аомл.), Германия (4 672 м^рА АОм..), Великобритания (3 255 млрА Аомм.), Франция (3 228 м^рА АОлм.), Италия (2 665 м^рА АОлм.), Канада (1 921 млрА Аомл.) и стабильно растет,

\section{Аинамика ВВП, численности населения, экспорта, импорта, объема ПИИ Китая} за 2010, 2019 гr.

\begin{tabular}{|c|c|c|c|c|c|c|}
\hline \multirow[b]{2}{*}{ ГоА } & \multicolumn{6}{|c|}{ Показатели } \\
\hline & $\begin{array}{c}\text { ВВП в тек. } \\
\text { ценах, } \\
\text { м^н Аол^. }\end{array}$ & $\begin{array}{c}\text { Численность на- } \\
\text { селения, } \\
\text { млн чел. }\end{array}$ & $\begin{array}{l}\text { Экспорт, } \\
\text { м^н АО^^. }\end{array}$ & $\begin{array}{l}\text { Импорт, } \\
\text { м^н АО^^. }\end{array}$ & $\begin{array}{c}\text { Объем накоп. } \\
\text { ПИИ, м^н Аом^. }\end{array}$ & $\begin{array}{c}\text { Численность } \\
\text { иммигрантов, } \\
\text { проживающих } \\
\text { в стране, млн чел. }\end{array}$ \\
\hline 2010 & 6087192 & 1368,811 & 1577754 & 1396247 & 586882 & 0,8499 \\
\hline 2019 & 14342934 & 1433,784 & 2499457 & 2078386 & 1769486 & 1 \\
\hline
\end{tabular}

Примечание: составлено авторами на основе обобщения материалов UNCTADstat / Data Center. URL: https://unctadstat. unctad.org/wds/TableViewer/tableView.aspx?Report; MIGRATION DATA PORTAL / Data Migration statistics. URL: https://www. migrationdataportal.org/international-data?i=stock_abs_\&t=2020\&cm49=40. 
Таблица 2

Показатели открытости экономики Китая за 2010 и 2019 гг.

\begin{tabular}{|c|r|r|r|r|r|r|r|}
\hline Гол & Кэ, \% & Ки, \% & $\begin{array}{c}\text { Квнеш, } \\
\%\end{array}$ & $\begin{array}{c}\text { Объем } \\
\text { экспорта } \\
\text { на душу насе- } \\
\text { ления, Аомл. }\end{array}$ & $\begin{array}{c}\text { Аоля } \\
\text { накопленных } \\
\text { ПИИ в ВВП, \% }\end{array}$ & $\begin{array}{c}\text { Объем накоплен- } \\
\text { ных ПИИ на душу } \\
\text { населения, Аомл. }\end{array}$ & $\begin{array}{c}\text { Аов в общей чис- } \\
\text { ленности населе- } \\
\text { ния, \% }\end{array}$ \\
\hline 2010 & 25,9 & 22,9 & 24,4 & 1152,65 & 9,64 & 428,75 & 0,06 \\
\hline 2019 & 17,43 & 14,49 & 15,96 & 1743,26 & 12,34 & 1234,13 & 0,07 \\
\hline
\end{tabular}

Примечание: рассчитано и составлено авторами на основе обобщения материалов: UNCTADstat / Data CenterURL: https://unctadstat.unctad.org/wds/TableViewer/tableView.aspx?Report.

Таблица 3

Аинамика основных макроэкономических показателей развития Китая

\begin{tabular}{|c|c|c|c|c|}
\hline ГОА & ВВП по ППС, м^рА АОм^. & $\begin{array}{c}\text { ВВП на душу } \\
\text { населения, Аол^. }\end{array}$ & Уровень безработицы, \% & Инфляция, \% \\
\hline 1980 & 302,73 & 307 & 4,9 & - \\
\hline 1985 & 648,60 & 293 & 1,8 & 9,3 \\
\hline 1990 & 1108,1 & 340 & 2,5 & 3,1 \\
\hline 1995 & 2228,7 & 594 & 2,9 & 17,1 \\
\hline 2000 & 3661,3 & 1041 & 3,1 & 0,4 \\
\hline 2005 & 6543,1 & 1747 & 4,2 & 1,8 \\
\hline 2010 & 12287,32 & 4500 & 4,1 & 3,3 \\
\hline 2015 & 17880,34 & 8085 & 4,1 & 1,4 \\
\hline 2016 & 18701,70 & 8120 & 4,0 & 2,0 \\
\hline 2017 & 19814,06 & 8823 & 3,9 & 1,6 \\
\hline 2018 & 21659,30 & 9920 & 3,8 & 2,1 \\
\hline 2019 & 23393,00 & 10522 & 3,6 & 2,9 \\
\hline
\end{tabular}

Примечание: составлено авторами на основе обобщения материалов: The World Bank. URL: https://data.worldbank.org/ indicator/ ; Human Development Reports. URL: http://hdr.undp.org/en/countries/profiles/.

начиная с 1980 г. По объему номинального ВВП, китайская экономика занимает второе место в мире, уступая мишь США.

Современный Китай является главным мировым экспортером товаров (табл. 4), что объясняется наличием мощнейшей индустриальной базы. KHP имеет самое большее в мире количество промышленных предприятий, прежАе всего - тяжёлой промышленности, на которых трудится более 3/5 работающего населения страны.

Помимо этого, КНР занимает второе место в мире по стоимости импорта товаров. В частности, статистика свидетельствует о том, что

Таблица 4

Страны - лидеры мирового экспорта и импорта в 2020 г.

\begin{tabular}{|c|c|c|}
\hline Страна & Объем экспорта, м^н Аом^. & Объем импорта, м^н Аом^. \\
\hline Китай & 2590221 & 2055752 \\
\hline США & 1431610 & 2407545 \\
\hline Германия & 1380647 & 1170787 \\
\hline Нидерланды & 674870 & 596746 \\
\hline Япония & 641319 & 634514 \\
\hline Гонконг & 548773 & 569769 \\
\hline Республика Корея & 512498 & 467633 \\
\hline Италия & 496120 & 422879 \\
\hline Франция & 488372 & 582351 \\
\hline Бельгия & 419892 & 394637 \\
\hline
\end{tabular}


страна входит в мировой топ вместе с США по импорту таких стратегически важных Аля развития национальной индустриальной товаров как черные металмы и нефть.

Страна постоянно увеличивает свои позиции в различных мировых рейтингах. В частности, КНР является еАинственным примером из 189 государств, ранжируемых по индексу человеческого развития (ИЧР), которому за триАцать лет уАалось наиболее сильно изменить свои позиции в соответствующей иерархии государств, повысив их на 12 пунктов. За период с 1990 по 2019 гг. значение соответствующего показателя возросло с 0,499 ао 0,761, соответственно. По Аругому комплексному показателю, позволяющему наиболее полно оценивать эффективность проводимых реформ, сильные и слабые стороны социального, экономического научно-технологического развития страны - индексу глобальной конкурентоспособности Всемирного экономического форума за период с 2005 по 2019 г. Китаю смог подняться с 46 на 28 место. Это очень значимый рост, особенно, если учесть, что за КНP на 30 месте находится Италия, на 32 месте - Чехия, на 34 месте - Португалия ${ }^{1}$.

Каковы причины столь успешного развития экономики страны?

Мы согласны с мнением большинства китаеведов о том, что в основе "китайского чуда", лежат Ава принципиальных аспекта.

Во-первых, это - специфические формы познания [2] и менталитет китайской нации [3], базирующиеся на комлективизме, преклонении переА Законом и рациональностью [4]. Хотя эти фундаментальные особенности народа зародимись еще Ао н.э. [5], по настоящее время именно они определяют отношение граждан страны к Власти и принимаемым ею решениям. Сохраняющие свою актуальность мегизм и "всеобщая комлективность" существенным образом упрощают подходы к управлению, как микро, так и макроэкономческими субъектами (включая и государство, в целом). А, формировавшиеся веками прагматизм, расчетливость и рациональность определяют трепетное и бережное отношение к Аеньгам и склонность браться за ^юбую возможность заработать. Эти столпы китайской илеологии формировались и совершенствовались веками. И, хотя в настоящее время они существенно отличаются от себя самих периода 3 тысячелетия н.э., они не только не поте-

1 The Global Competitiveness Report 2019. URL: https:// www3.weforum.org/docs/WEF_TheGlobalCompetitivenessR eport2019.pdf. ряли своей актуальности, но поАтверАили свое "абсолютное преимущество" переА Аемократиями, постепенно теряющими свой суверенитет и культурную идентичность [6, с. 56] в периоА глобализации [7].

Вторым триггером Аостижения Китаем с конца XX в. и по настоящее время высоких значений макроэкономических показателей, безусловно, являются грамотные внутриэкономические реформы, начатые в 70-х гг. XX в. Аэн Сяопином и последующее за ними повышение открытости национальной экономики. Новые Аля страны финансовая, инвестиционная и внешнеторговые политики разрабатывались правительством тщательнейшим образом, внеАрялись поэтапно и, естественно, принесли свои положительные результаты не сразу. В частности, реформа финансовой сферы (широкомасштабная миберализация цен, установление еАиного плавающего валютного курса юаня, разработка системы распределения Аоходов между субъектами и сбора налогов и Ар.) заняла поряАка Аесяти мет, прошла в три этапа и только к концу 80-х гг. позволила выйти на налоговое законодательство, отвечающее интересам всех национальных экономических субъектов.

Работа правительства страны по привлечению иностранных инвестиций приняла широчайший размах:

- было инициировано активное созАание "особых экономических зон";

- проводилась работа по привлечению в страну кредитов по программам организации объеАиненных наций $(\mathrm{OOH})$ и от Всемирного банка (ВБ);

- были разработаны и внедрены законы о контрактах и патентах, представляющие интерес, как Аля национальных, так и иностранных преАприятий;

- была создана база Аля формирования в последующем (начало 90-х гг.) фондовых бирж и пр.

В свою очередь, открытие страны Аля внешнего мира произошло в случае с КНP не насильственным путем руками внешних игроков (иностранных государств, интеграционных объединений, международных организаций), а в результате проведения продуманных реформ в духе внешнеэкономической миберализации. В большинстве своем они были направлены на генерирование национальных конкурентных преимуществ посреАством активного использования передовой зарубежной техники, технологий, опыта организации производства [8]. 
Следует отметить, что кроме вышеназванных рыночных реформ огромное влияние на укрепление позиций Китая в мировой экономике оказали и структурные трансформации. Страна совершила переход от использования народных коммун к практике семейного поАряла, что стало основой Аля второго Аыхания индустриализации. При этом, если в 1950 1970-е гг. правительство КНР было сфокусировано на развитии тяжелой промышленности [9, с. 114], то, начиная с 1980-х гг., центр тяжести смещается на легкие по трудоемкости отрасли производства. В результате, использование национальных ресурсов становится более рациональным, эффективным, а это само по себе является преАпосылкой Аля ускорения прироста ВВП.

Оказавшись весьма эффективными, начатые в КНР во второй половине XX в. преобразования, были продолжены правительством страны и далее путем реализации концепции «новой нормальности". ПерехоА от экономического роста, ориентированного на количественные показатели, к росту, предполагающему улучшение его качества, развитие современных конкурентоспособных кластеров, создание китайских брендов - все это стало содержанием плана "Произведено в Китае - 2025" [10].

В настоящее время Китай постепенно переходит от интенсивного использования факторов производства "первой природы" (Аешевого труда) к использованию факторов “второй природы" - информационных технологий, роботизации производства. Начиная с 2010-х гг. основным триггером структурной эволюции экономики Китая становится интенсивное раз- витие сферы услуг, в целом и технологического, информационного сектора, в частности.

По Аанным министерства статистики Китая в 2020 г. общий вкиаА в ВВП от IT-сектора страны, вкмючающего произвоАство программного обеспечения (ПО), телекоммуникации и информационные технологии, составил 587,4 млрА Аом.. Это на 16,9 \% выше, чем годом ранее, несмотря на то, что эпидемия коронавируса привела к снижению Аанного показателя, как и во многих других секторах экономики страны. Сегодня к числу ведущих технологических компаний КНР, занимающих значимые места в мировых рейтингах, относятся: Alibaba, ByteDance, Tencent, Baidu, Xiaomi и ар. Благодаря высокому уровню развития именно этих компаний (табл. 5), Китай продолжает демонстрировать стабильный экономический рост. В частности, в 2020 г. прирост ВВП Китая состави^ 2,3 \% при этом мировой ВВП снизился на 3,8 \%².

Стоить отметить, что изначально, во время роста IT-сектора, власти Китая старались защищать его от сторонней конкуренции посреАством регулирующих и протекционистских мер, но в 2021 г. соответствующая отраслевая политика страны начинает кардинально меняться.

В марте 2021 г. в экономическом плане на последующие 5 лет руководство КНР впервые упоминает о необходимости усиления контроля государства наА Аеятельностью информационных технологических компаний. В послеАующем принимает ияи активно корректирует уже Аействующие законы, регулирующие соответствующую сферу.

2 The World Bank. URL: https://data.worldbank.org/ indicator/NY.GDP.MKTP.KD.ZG?view=chart.

Таблица 5

Аинамика оборота крупнейших технологических компаний КНР

\begin{tabular}{|c|c|c|c|c|}
\hline Компания & Отрасль & $\begin{array}{c}\text { Оборот } 2020 \text { г., } \\
\text { МАн АОМм. }\end{array}$ & $\begin{array}{c}\text { Оборот } 2011 \text { г., } \\
\text { МАн АОМм. }\end{array}$ & $\begin{array}{c}\text { Прирост оборота по сравнению } \\
\text { с базисным годом, \% }\end{array}$ \\
\hline Tencent Holding & IT ХОЛАИНГ & 69851 & 2908 & 1481,41 \\
\hline Alibaba Group & $\begin{array}{l}\text { Электронная коммер- } \\
\text { ция }\end{array}$ & 71985 & 978 & 7260,43 \\
\hline Meituan & $\begin{array}{l}\text { Аоставка еАы, } \\
\text { товаров, услуг }\end{array}$ & 17219 & $1558(2016)$ & 1005,20 \\
\hline China Mobile & Телекоммуникации & 111293 & 71766 & 55,08 \\
\hline Huawei & Телекоммуникации & 133710 & 32396 & 312,74 \\
\hline Xiaomi & Бытовая техника & 36879 & $10021(2015)$ & 268,02 \\
\hline Baidu & Социальные сети & 16410 & 2303 & 612,55 \\
\hline
\end{tabular}

Источники: Составлено авторами на основе обобщения материалов: Tencent Holding. URL: https://www.tencent.com/ en-us/investors/financial-reports.html; Alibaba Group. URL: https://www.alibabagroup.com/en/ir/reports; Maituan. URL: http:// meituan.todayir.com/html/index.php; China Mobile Itd. URL: https://www.chinamobileltd.com/en/ir/reports.php; Huawei. URL: https://www.huawei.com/en/annual-report; Xiaomi. URL: https://company.mi.com/en-us/ir/financiallnfo/; Baidu. URL: https:// ir.baidu.com/financial-reports/. 
Во главу угла ставятся вопросы о кибербезопасности страны, которые начали на законодательном уровне прорабатываться еще с 2016 г. 10 июня 2021 г. принимается и 1 сентября того же года вступает в силу соответствующий Закон $^{3}$. Его основная цель - классифицировать информацию, которую собирают частные компании, по уровню ее важности Аля соблюАения национальных интересов.

Летом того же года Китайское правительство превентивно публикует список, включающий в себя 105 приложений, содержащих информацию об информационных продуктах, генерируемых на территории страны и нарушающих национальное законодательство, среАи них крупнейшие продукты ведущий IT-компаний Китая: Douyin, Kugou, Baidu и Ар. Помимо публикации списка, власти Китая накладывают ограничения на многие компании технологического сектора. Им предписывается “реструктурировать свои финансовые подразделения в единый холАинг и разорвать "неправомерные связи" межАу своими платежными сервисами и финансовыми продуктами"4.

Кроме ужесточения законодательства в рамках сбора и хранения информации, ЦК партии Китая фактически приостанавливает функционирование компаний, предоставляющих цифровое, интернет - образование, путем введения запрета на проведение IPO и привлечение каких-либо зарубежных инвестиций, в том числе от зарубежных Аочек китайских компаний. $\mathrm{K}$ тому же власти полностью запрещают внешкольные занятия в выходные и праздники, а также занятия с Аошкольниками. Аанные ограничения не позволяют компаниям Аанного сектора привлекать какие-либо инвестиции Аля расширения своего бизнеса 5 .

Кроме сферы онлайн - образования, правительство КНР ужесточило правила работы сервисов Аоставки еАы, а именно изменило рекомендуемые условия труда Аля курьеров, которые являются важнейшим звеном в работе соответствующих сервисов. Теперь серви-

\footnotetext{
${ }^{3}$ Закон о кибербезопасности КНР от 7 ноября 2016 г. URL: http://www.cac.gov.cn/2016-11/07/c_1119867116.htm.

4 "Кто контролирует Аанные, владеет инициативой". Как Китай Аобрался Ао каждого пользователя в интернете // thebell.io. 2021. URL: https://thebell.io/kto-kontroliruetdannye-vladeet-initsiativoj-kak-kitaj-dobralsya-do-kazhdogopolzovatelya-v-internete.

5 中共中央办公厅国务院办公厅印发《关于进一步 减轻义务教育阶段学生作业负担和校外培训负担的意 见》. URL: http://www.moe.gov.cn/jyb_xxgk/moe_1777/ moe_1778/202107/t20210724_546576.html.
}

сы Аолжны подАерживать уровень заработка курьеров не ниже минимальной зарплаты в регионе, где работают курьеры, а также предоставить им Аоступ к социальному страхованию, созАать профсоюзы и гарантировать курьерам членство в них ${ }^{6}$.

Также в 2021 г. власти Китая срывают крупнейшее IPO среди не только китайских компаний, но и среАи всех компаний в целом. IPO Ant. group суммарно Аолжно было помочь компании привлечь 34 млрА Аол^., при оценке выше 313 м^рА Аом. В^асти страны высказываются против провеАения IPO, после чего его проведение приостанавливается.

Еще оАним примером того, как правительство КНР активно контролирует деятельность своих информационных технологических компаний, является расследование против агрегатора такси Didi (Китайский аналог Uber) по итогам проведения ею IPO на 4.4 млрА Аом. В Аанном случае, руководство страны просто потребовало уАалить приложения, приналлежащие Didi, из всех магазинов приложений в Китае.

Перечисленные примеры имеют своим слеАствием подрыв Аоверия инвесторов к акциям китайских компаний, повышению рискованности их Аеятельности, вплоть Ао поглощения или банкротства. ОАнако, по мнению властей, они могут привести к оправданным соответствующими рисками полезностям:

- усилить государственный контроль наА IT-сектором страны;

- установить государственный контроль наА информацией о пользователях, которой обладают ведущие IT-компании Китая;

- предотвратить утечку Аанных за границу.

Согласно принятой в стране идеологии, авторитет и власть Партии являются незыблемыми, и, если крупные, пусть даже отечественные, компании начинают осуществлять попытки оказать влияние на ее политику, то это просто неприемлемо. В связи с этим, государственный контроль наА Аеятельностью ІТ-гигантов в чистом виде обосновывается национальными интересами и безопасностью. Ярким примером соответствующего прецедента является "наказание" оАной из крупнейших IT-компаний Китая после того, как Ажек Ма - основатель Alibaba Group публично раскритиковал Аействия правительства.

${ }^{6}$ China Stocks in U.S. Suffer Biggest Two-Day Wipeout Since 2008 // Bloomberg.com. 2021. URL: https://www. bloomberg.com/news/articles/2021-07-26/down-650-billion-chinese-stocks-in-u-s-set-for-even-more-pain?sref=cus8. 
Контроль наА информацией Аля китайского правительства является важнейшим рычагом Аля управления страной. В эпоху, когАа влаАение информацией позволяет правительству полностью контролировать повеАение общества, а также осуществлять превентивные меры по отношению к неудобным слоям общества, утечка Аанных, в первую очередь в сторону Запада, увеличивает риск гарантии национальной безопасности и Аает США Аополнительные преимущества. Именно поэтому китайское правительство стремиться минимизировать каналы Аля их утечки.

ОчевиАНо, что КонфАикт МеЖАУ ЦК Партии KHP и IT-компаниями тормозит развитие последних и ухудшает их инвестиционную привлекательность. Тем не менее, контроль наА ними - мировой трена 2021 г. $^{7}$ и те страны,

\footnotetext{
${ }^{7}$ Global Drive to Control Big Tech / Freedom House. URL:
}

которые не смогут его установить, рискуют кишиться своих позиций в гонке за лидерство в цифровой среАе, в частности и в структуре мирового поряака, в целом.

Мы полагаем, что Китай не остановится на Аостигнутых результатах. С большой Аолей вероятности он продолжит наращивать свою производственную мощь, увеличивать объемы как внутреннего, так и внешнего рынка, гибко реагировать на мировые тренды и корректировать, согласно происходящим изменениям, свою макроэкономическую политику. Конечно, этого неАостаточно Аля того, чтобы в среАнесрочной перспективе стать развитым госуАарством. ОАнако сократить разрыв с США по емкости своей экономики, ему удается.

https://freedomhouse.org/sites/default/files/2021-09/ FOTN_2021_Complete_Booklet_09162021_FINAL_ UPDATED.pdf.

\section{Список использованной китературы}

1. Минцзюнь. Китай: социально-экономическое развитие и внешняя торговля / Хэ Минцзюнь, ^.В. Шкваря, Ван Сичжэ. - DOI 10.31857/S032150750012178-7 // Азия и Африка сегодня. 2020. - № 11. - C. 11-16.

2. Богодельникова А.А. Проблема построения целостной картины мира: человекоразмерность научного и ненаучного познания / ^.A. Богодельникова. - DOI 10.17150/25002759.2020.30(4).566- 574 // Известия Байкальского государственного университета. - 2020. T. 30, № 4. - C. 566-574.

3. Матвеева Ю.В. Формирование и основные особенности менталитета китайцев / Ю.В. Матвеева // Культура. Ауховность. Общество. - 2012. - № 1. - С. 266-270.

4. Balashova M.A. The influence of mentality on the development of Chinese economy / M.A. Balashova, A.S. Sharunova // Science and innovations 2021: development directions and priorities : International Conference, Melbourne, November 10, 2021. - Melbourne, 2021. - P. 14-19.

5. Чен Хунцзе. Особенности исторического сложения религий Хань и Аругих национальностей Китая / Чен Хунцзе // Символ науки. - 2015. - № 12. - С. 69-73.

6. Звездина И.П. Влияние процессов глобализации на культуру китайской Народной Республики / И.П. Звездина // Научный журнал. - 2019. - № 2. - С. 51-59.

7. РанАжан Р. Теоретический анализ зарубежных когнитивных теорий личности / Р. РанАжан. DOI 10.17150/2411-6262.2021.12(1).22 // Baikal Research Journal. - 2021. - T. 12, № 1. - URL: http://brj-bguep.ru/reader/article.aspx?id=24393.

8. Ши Икэ. Влияние внешнеторговой политики на экономическое развитие Китая / Ши Икэ, H.P. Эпова. - DOI 10.17150/2587-7445.2021.5(1).25-35 // Российско-китайские исследования. 2021. - T. 5, № 1. - C. 25-35.

9. Мозиас П.М. Структурные савиги в экономике Китая / П.М. Мозиас. - DOI 10.31249/ rva/2021.04.091 // Социальные и гуманитарные науки. Отечественная и зарубежная митература. Серия 9: Востоковедение и африканистика. - 2021. - № 4. - С. 112-142.

10. Арузик Я.С. Свободные экономические зоны / Я.С. Арузик. - Москва : Юрайт, 2018. - 135 с.

\section{References}

1. He Mingjun, Shkvarya L.V., Wang Xizhe China: Socio-Economic Development and Foreign Trade. Aziya I Afrika segodnya = Asia and Africa today, 2020, no. 11, pp. 11-16. (In Rusian). DOI: 10.31857/ S032150750012178-7.

2. Bogodelnikova L.A. Towards a Holistic Worldview: Human-Sizedness of Scientific and Non-Scientific Cognition. Izvestiya Baikal's kogo gosudarstvennogo universiteta = Bulletin of Baikal State University, 2020, vol. 30, no. 4, pp. 566-574. DOI: 10.17150/2500-2759.2020.30(4).566-574. (In Russian). 
3. Matveeva Yu.V. The making and main features of the Chinese mindset. Kultura. Dukhovnost. Obshchestvo = Культура. Ауховность. Общество, 2012, no. 1, pp. 266-270. (In Russian).

4. Balashova M.A., Sharunova A.S. The Influence of Mentality on the Development of Chinese Economy. Science and Innovations 2021: Development Directions and Priorities. International Conference, Melbourne, November 10, 2021. Melbourne, 2021, pp. 14-19.

5. Chen Khuntsze. Features of the historical composition of the religions of Han and other nationalities of China. Simvol nauki = Symbol of Science, 2015, no. 12, pp. 69-73. (In Russian).

6. Zvezdina I.P. The Impact of Globalization Processes on the Culture of the People's Republic of China. Nauchnyi zhurnal = Scientific Journal, 2019, no. 2, pp. 51-59. (In Russian).

7. Ranjan R. Theoretical Analysis of Foreign Cognitive Personality Theories. Baikal Research Journal, 2021, vol. 12, no. 1. (In Russian). DOI: 10.17150/2411-6262.2021.12(1).22.

8. Shi Ike, Epova N.R. The Impact of Foreign Trade Policy on China's Economic Development. Rossiisko-Kitaiskie Issledovaniya = Russian and Chinese Studies, 2021, vol. 5, no. 1, pp. 25-35. (In Russian). DOI: 10.17150/2587-7445.2021.5(1).25-35.

9. Mozias P.M. Structural Shifts in China's Economy. Sotsial'nye i gumanitarnye nauki. Otechestvennaya i zarubezhnaya literatura. Seriya 9: Vostokovedenie $i$ afrikanistika = Social Sciences and Humanities. Domestic and Foreign Literature. Series 9: Oriental and African Studies, 2021, no. 4, pp. 112142. (In Russian). DOI: 10.31249/rva/2021.04.091.

10. Druzik Ya.S. Free Economic Zones. Moscow, Yurait Publ., 2018. 135 p.

\section{Информация об авторах}

Балашова Мария Александровна - кандидат экономических наук, Аоцент, кафедра мировой экономики и экономической безопасности, Байкальский государственный университет, г. Иркутск, Российская Федерация, e-mail: mabalashova@mail.ru.

Труфанова Анастасия Алексеевна - студент, кафедра мировой экономики и экономической безопасности, Байкальский государственный университет, г. Иркутск, Российская Федерация, е-таil: truanastasia.irk@gmail.com.

Трошкин Матвей Игоревич - студент, кафедра мировой экономики и экономической безопасности, Байкальский государственный университет, г. Иркутск, Российская Федерация, e-mail: botmatvey@gmail.com.

\section{作者信息}

Maria A. Balashova - 经济学副博士，副教授，世界经济与经济安全系经济，贝加尔国立大学， 伊尔库茨克，俄罗斯联邦，邮箱: mabalashova@mail.ru.

Anastasiia A. Trufanova - 学生，世界经济与经济安全系学生，贝加尔国立大学，俄罗斯联邦， 伊尔库茨克，邮箱: truanastasia.irk@gmail.com.

Matvey I. Troshkin - 学生，世界经济与经济安全系学生，贝加尔国立大学，俄罗斯联邦，伊尔 库茨克，邮箱: botmatvey@gmail.com.

\section{Authors}

Maria A. Balashova - PhD in Economics, Associate Professor, Department of World Economics and Economic Security, Baikal State University, Irkutsk, Russian Federation, e-mail: mabalashova@mail.ru.

Anastasiia A. Trufanova - Student, Department of World Economics and Economic Security, Baikal State University, Irkutsk, Russian Federation, e-mail: truanastasia.irk@gmail.com.

Matvey I. Troshkin - Student, Department World Economics and Economic Security, Baikal State University, Irkutsk, Russian Federation, e-mail: botmatvey@gmail.com.

\section{Аия цитирования}

Балашова М.А. О причинах устойчивого развития экономики Китая в XX - XXI вв. / М.А. Балашова, А.А. Труфанова, М.И. Трошкин. - DOI 10.17150/2587-7445.2021.5(4).223-231 // Российско-китайские исследования. - 2021. - Т. 5, № 4. - С. 223-231.

\section{For Citation}

Balashova M.A., Trufanova A.A., Troshkin M.I. On the Reasons of China's Stable Economic Development in the XX - XXI Centuries. Rossiisko-Kitaiskie Issledovaniya = Russian and Chinese Studies, 2021, vol. 5, no. 4, pp. 223-231. (In Russian). DOI: 10.17150/2587-7445.2021.5(4).223-231. 